\title{
La EPESA, un proyecto de cooperación internacional
}

\author{
Dr. Mario Melgar Adalid
}

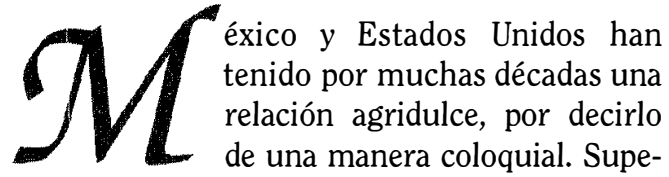
rada casi la traumática amputación de nuestro territorio, los dos países hemos aprendido a vivir una relación compleja y difícil, pero al mismo tiempo llena de posibilidades y promesas a futuro. La relación entre los dos países se ha percibido de manera diferente, como por ejemplo la frase atribuida a Porfirio Díaz de "Pobre México, tan lejos de Dios y tan cerca de Estados Unidos", la de Alan Riding de "Vecinos Distantes" y la del académico Sydney Weindraub de que nuestros dos países tienen un matrimonio por conveniencia.

Estamos ligados indisolublemente por la historia $y$ por la geografía. Compartimos una enorme frontera, la única que divide a un país altamente industrializado, de un país como México, en proceso de desarrollo. La colaboración es por ello una manera necesaria para fortalecer nuestros vínculos y para crear relaciones mejores, más sólidas, fructíferas y dignas para quienes compartimos una región tan importante del globo. Una forma de colaboración es a través de los intercambios de las diferentes manifestaciones culturales y sociales, además de la interrelación económica y comercial.

El medio indispensable para cualquier intercambio es la lengua. A través de la lengua se da la primera forma de comunicación entre las personas. Es el vehículo de las ideas. Por ello es tan inmediata la comunicación de México con los pueblos de habla hispana y por ello tenemos que seguir construyendo las vías de comunicación con quienes no hablan nuestra lengua.

La colaboración no es, ni debe ser asunto exclusivo de los gobiernos o de los aparatos estatales que por razones de política internacional establecen formas institucionales de cooperación e intercambio. Además de mejorar esta relación que, por supuesto, es la más relevante y fundamental, también es indispensable generar otras formas de colaboración. Las organizaciones académicas, culturales y sociales tienen un amplio campo de actuación para avanzar en estrechar vínculos y crear nuevas formas de cooperación.

Es necesario que las organizaciones de todos los órdenes actúen y participen colaborando en la creación de relaciones renovadas, nuevas, útiles y rentables desde cualquier punto de vista: financiero, social, cultural, humano, artístico y académico. En este sentido, la UNAM es una institución que ha participado activamente en las líneas de colaboración entre México y el exterior. Una de las acciones cooperativas de la UNAM fue el establecimiento $y$ operación de una escuela de extensión en Estados Unidos con el objeto de promover un mejor entendimiento entre las dos naciones, haciendo uso de su arsenal académico, estrechando relaciones $y$ buscando nuevas formas de cooperación bilateral.

La presencia de la UNAM en San Antonio se remonta a 1944, cuando un grupo de mexicanos y méxico-americanos consideró necesario dotar a la ciudad de San Antonio de un espacio cultural y educativo que favoreciera el rescate de sus tradiciones. Fijaron su atención

*Director de la Escuela Permanente de Extensión de la UNAM en San Antonio, Texas, (EPESA) 
en la Universidad Nacional Autónoma de México. La UNAM, considerada en México como el proyecto cultural más importante del siglo xx, inició cursos de extensión universitaria y se dio la tarea de promover la cultura enviando sistemáticamente a distinguidos profesores universitarios. A partir de 1972, con el apoyo del Cabildo de la ciudad de San Antonio, la UNAM adquirió presencia permanente, ofreciendo sus programas durante todo el año, mediante el establecimiento formal de una Escuela de extensión.

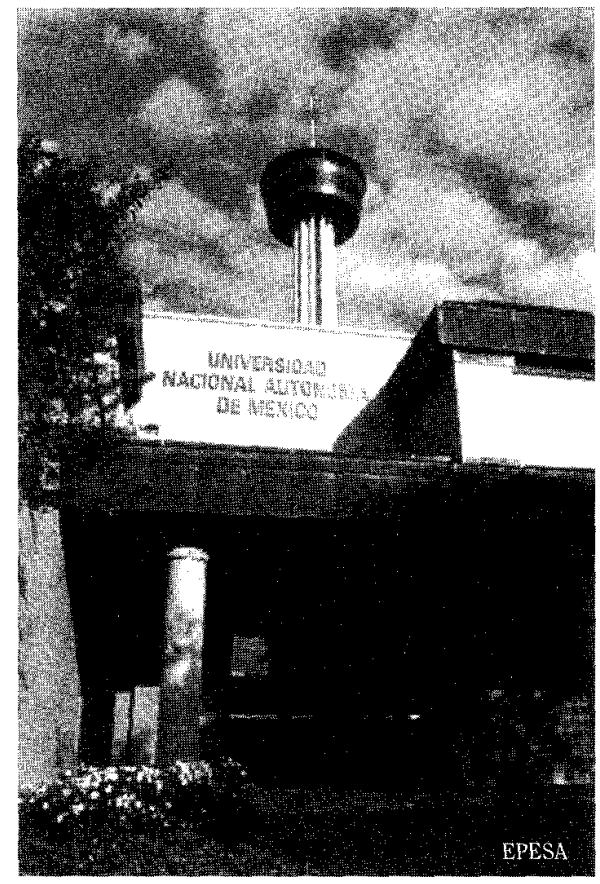

La Escuela de la UNAM en

San Antonio Texas, esta inserta en el Centro de Enseñanza Para Extranjeros de la UNAM (CEPE), dependencia que cumplió ochenta años de servir a la comunidad universitaria en la tarea vincular a los estudiantes interesados en nuestra lengua y cultura con sus programas educativos y académicos. La Escuela es un magnífico vehículo para fortalecer los lazos culturales, económicos $y$ sociales entre mexicanos $y$ estadunidenses.

La Escuela Permanente de Extensión, ubicada en el corazón de San Antonio, en el parque Hemisferia, desarrolla una intensa actividad cultural y educativa. Desde sus inicios, la EPESA es reconocida como una de las mejores escuelas de enseñanza, tanto del español y la cultura de México, como del inglés como segunda lengua que inició en 1983. El prestigio alcanzado se debe a que los cursos son impartidos por profesores nativo hablantes que mantienen el rigor académico que caracteriza a la UNAM. Constantemente se hace una revisión del plan de estudios y se elaboran nuevos y novedosos materiales de enseñanza. Por otra parte, la EPESA también juega un papel relevante al servir de enlace entre los diversos programas académicos, de investigación y difusión cultural de la UNAM y centros en Estados Unidos con actividades afines.

El español se ha convertido en una lengua importante. Esto se atribuye, amén del número creciente de personas que lo habla en el mundo, por una parte, a los fenómenos migratorios. Las proyecciones demográficas indican que para el año 2050, el 25 por ciento de la población de Estados Unidos será de origen hispano. Existen además factores como los flujos comerciales y el intercambio cultural y social entre México y Estados Unidos que suponen un intercambio en el conocimiento, cada vez más generalizado, del español y el inglés, en los dos países. Mientras que para la población anglohablante el interés por comunicarse en español sigue aumentando, para los mexicanos hablar y entender inglés ha sido una necesidad desde hace décadas. En el cumplimiento de fortalecer los lazos de comunicación y entendimiento entre ambas naciones, la Escuela ha sido un magnífico vehículo para la difusión de la lengua y la cultura de ambos países.

Uno de los esfuerzos que la EPESA ha realizado a partir de 1995, es un proyecto dirigido a sensibilizar a alumnos destacados de distintas facultades $y$ escuelas de la UNAM a la cultura estadunidense. El programa de estudios incluye cursos intensivos de inglés además de un programa de inmersión que les permite 
conocer más de cerca algunas particularidades de la vida social, familiar y de las organizaciones políticas, académicas y de negocios de Estados Unidos.

A partir del año 2002 y durante los próximos cinco años, la empresa HEB, que desarrolla una intensa actividad comercial en la región sur de Estados Unidos ha iniciado operaciones en varias ciudades del norte de México y asumirá el financiamiento de este programa. Los estudiantes Mexicanos que atiendan este programa serán evaluados, si tienen interés en ello, para considerar su incorporación laboral a las áreas de sus especialidades, sea en México o en Estados Unidos. La colaboración de empresas comerciales privadas de Estados Unidos prueba la posibilidad de colaboración a futuro entre organizaciones no necesariamente gubernamentales, interesadas en el mejoramiento de nuestras relaciones $y$ convencidas de la eficiencia, calidad y seriedad de los programas universitarios. Un beneficio más para los estudiantes que participen en este programa es la posibilidad de formar parte del personal de esta empresa ya sea en México o en Estados Unidos.

La exitosa labor que la UNAM ha desarrollado en San Antonio condujo a la decisión de seguir el modelo de la EPESA para abrir una escuela de extensión en Hull, Canadá, en 1995, y la que recientemente inició actividades en Chicago, Illinois.

La complejidad $y$ variedad del flujo migratorio han creado nuevos fenómenos que deben ser atendidos por todos los actores: políticos, académicos, sociales, económicos y culturales en ambos países, En este sentido, en 2001 la UNAM dio un importante paso al celebrar con la Secretaría de Relaciones Exteriores un Convenio de Colaboración. De acuerdo con éste, la UNAm llevará al exterior programas de atención a las comunidades mexicanas, en particular los de orden académico, educativo y cultural. Esta iniciativa agrega a las actividades tradicionales de la EPESA, la tarea de apoyar a los mexicanos para una mejor integración a la vida social, cultural y laboral en Estados Unidos.

Con el objeto de apoyar estas acciones, se han iniciado varios programas con la colaboración de empresas estadunidenses que operan también en nuestro país. Este año, la UNAM en San Antonio inició un programa auspiciado por la empresa Western Union para impartir cursos de "inglés de sobrevivencia" a mexicanos que viven en Estados Unidos y que no han tenido oportunidad de aprender esta lengua. El objetivo es darles herramientas, además de conocimientos básicos de inglés para que su vida cotidiana sea mejor, más productiva, más digna y que mantengan la seguridad en sí mismos y el orgullo de ser mexicanos.

De igual manera, se ha iniciado un programa de bachillerato a distancia, también patrocinado por Western Union, que pretende apoyar a mexicanos que por razones migratorias abandonaron sus estudios en nuestro país y no pudieron continuar con su educación.

Se ha dicho que San Antonio es la ciudad más mexicana que existe fuera de México. Las razones son entre otras su cercanía geográfica con la frontera y la combinación de factores que le dan a esta ciudad un carácter internacional muy mexicano. Las razones pueden ser históricas como la estancia de Benito Juárez en el exilio o la formulación, en esta ciudad, de los planes revolucionarios de Francisco I. Madero y los hermanos Serdán. También influyó la presencia de mexicanos desplazados por la revolución, que se asentaron en esta ciudad tejana. Muchas pueden ser las razones que expliquen la mexicanidad de San Antonio, no obstante, la presencia de la UNAM en esta ciudad, ha contribuido a generar la idea de que México $y$ Estados Unidos pueden y deben encontrar vías de colaboración, amistad y entendimiento que permitan avisorar cada vez mejores relaciones entre los dos países. 56 años de trabajo permanente así lo acreditan 